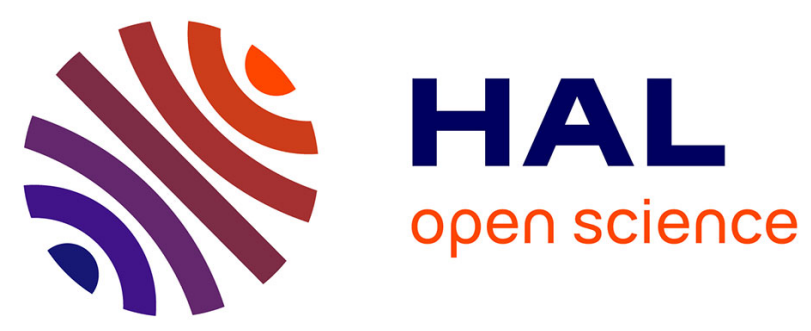

\title{
Micrometer resolved inspection of defects and laser damage sites in UV high-reflecting coatings by photothermal displacement microscopy
}

\author{
A. Bodemann, N. Kaiser, M. Reichling, E. Welsch
}

\section{- To cite this version:}

A. Bodemann, N. Kaiser, M. Reichling, E. Welsch. Micrometer resolved inspection of defects and laser damage sites in UV high-reflecting coatings by photothermal displacement microscopy. Journal de Physique IV Proceedings, 1994, 04 (C7), pp.C7-611-C7-614. 10.1051/jp4:19947144 jpa-00253202

HAL Id: jpa-00253202

https://hal.science/jpa-00253202

Submitted on 1 Jan 1994

HAL is a multi-disciplinary open access archive for the deposit and dissemination of scientific research documents, whether they are published or not. The documents may come from teaching and research institutions in France or abroad, or from public or private research centers.
L'archive ouverte pluridisciplinaire HAL, est destinée au dépôt et à la diffusion de documents scientifiques de niveau recherche, publiés ou non, émanant des établissements d'enseignement et de recherche français ou étrangers, des laboratoires publics ou privés. 


\title{
Micrometer resolved inspection of defects and laser damage sites in UV high-reflecting coatings by photothermal displacement microscopy
}

\author{
A. Bodemann, N. Kaiser, M. Reichling* and E. Welsch** \\ Fraunhofer-Einrichtung für Angewandte Optik und Feinmechanik, Schillerstrasse 1, 07745 Jena, \\ Germany \\ * Fachbereich Physik, Freie Universität Berlin, Arnimallee 14, 14195 Berlin, Germany \\ ** Institut für Optik und Quantenelektronik, Friedrich-Schiller-Universität Jena, Max-Wien-Platz 1, \\ 07743 Jena, Germany
}

\begin{abstract}
Characteristic features of defects in dielectric multilayer UV-mirrors are determined by photothermal displacement imaging. A large number of micron sized absorbing defects are detected, however, their size and absorption strength distribution strongly depends on thin film preparation conditions. It is found that all features well correlate with thin film damage thresholds at $248 \mathrm{~nm}$.

An enhanced photothermal amplitude in a halo around ablation spots damaged by high fluence UV light indicates thin film delamination resulting from thermoelastic stress during laser irradiation.
\end{abstract}

\section{INTRODUCTION}

Since the advent of high-power laser systems, laser-damage thresholds are an important figure-of-merit for dielectric coatings used in optical systems guiding the laser light [1]. The design of advanced coating systems that are able to withstand laser intensities of the order of $\mathrm{GW} / \mathrm{cm}^{2}$ is a challenging task for thin film manufacturers. Demands on coating quality are especially high at the boundaries of the spectral region accessible for lasers. Coatings for the infra-red [2] and ultra-violet [3] often suffer from residual absorptions at these extreme wavelengths resulting from defects produced during thin film deposition or developing during atmospheric exposure.

Various methods have been proposed to determine damage thresholds for optical coatings. All techniques that have been used so far are based on systematically irradiating samples with various fluences below and above the damage threshold and recording a specific phenomenon connected with an irreversible change in coating properties; i.e. the coating is damaged during the process of testing.

The long-term aim of measurements as presented in the present paper is the development of a predictive technique that allows the determination of the damage threshold without damaging the sample during the test procedure. The basic idea of such a non-destructive threshold determination is to correlate properties of defects that are crucial for the damage process and can be measured utilizing a non-invasive photothermal probe with the damage thresholds for a series of test samples. Thus an empirical relation between defect properties and damage threshold may be determined that can be used for a prediction of thresholds for unknown systems.

The purpose of the present paper is a first step in this direction. Selected areas of high-reflecting (HR) multilayer coatings for $248 \mathrm{~nm}$ excimer laser radiation are scanned with a photothermal microscope and resulting defect maps are systematically investigated by simple statistic procedures to classify the coating systems with respect to defect density, defect size and absorption strength distributions as well as background absorption. Data is collected for a variety of samples and correlated with damage thresholds independently determined by a conventional standard technique. 


\section{EXPERIMENTAL}

Measurements were performed on HR coatings consisting of typ. 41 alternating layers of $\mathrm{Al}_{2} \mathrm{O}_{3}$ and $\mathrm{SiO}_{2}$ with an optical thickness of $\lambda / 4$ on SQ1 quartz substrates. Thin films were deposited by electron beam evaporation and the systems were covered with a $\lambda / 2$ protection layer $\mathrm{SiO}_{2}$ on top of the stack. To obtain samples of different quality various conditions have been changed during the deposition process or samples have been subject to a special post-production treatment. Damage thresholds have been determined with a standardized equipment described in detail elsewhere [4].

In this paper we report on results from three typical coatings furtheron labelled A,B, and C. Sample A represents a low quality system deposited under normal conditions without any additional treatment. The same growth conditions have been applied for sample B, however, the surface of this system was covered by an additional removable protective layer for the time between deposition and first use. Sample $\mathrm{C}$ was a high-quality specimen that had been grown from highest-purity materials under improved vacuum conditions. According to the varied deposition conditions different excimer laser damage thresholds were found. Damage measurements yielded threshold values of $0.61 \mathrm{~J} / \mathrm{cm}^{2}, 3.0 \mathrm{~J} / \mathrm{cm}^{2}$, and $16 \mathrm{~J} / \mathrm{cm}^{2}$, for samples $\mathrm{A}, \mathrm{B}$, and $C$, respectively. While sample $A$ has to be regarded as waste, sample $C$ with an extraordinarily high laser damage resistance represents a coating quality from the top of the spectrum obtainable with state-ofthe-art thin film deposition equipment.

Microscopy measurements were performed with a photothermal apparatus operated in the displacement mode at $1 \mathrm{kHz}$ modulation frequency. Images shown in this paper represent the variation of the amplitude of the photothermally induced in-plane-deflection of the probe beam for two-dimensional scans on the sample surface. The $4 \mu \mathrm{m}$ lateral resolution of the displacement images was limited by the $25 \mu \mathrm{m}$ focal diameters of pump and probe beam. A more detailed description of the photothermal microscope as well as an introduction to displacement microscopy on optical coatings can be found elsewhere $[5,6]$.

\section{DEFECT IMAGING}

Fig. 1 shows two-dimensional photothermal amplitude images over regions of $800 \times 800 \mu \mathrm{m}^{2}$ from samples $A, B$, and C, respectively. Distinct differences appear in the images for samples of different quality. The image for sample A reveals a strong background absorption signal over the entire scanned area and a large number of randomly distributed defects varying in size and absorption strength. Defect density appears to be similar for sample B, however, the background signal is much smaller compared to the absorption peak amplitudes. A completely different result is found for the high quality sample $\mathrm{C}$. Background absorption is close to the detection limit in this case and only a small number of weakly absorbing defects can be identified. These defects exhibit different shapes and, therefore, seem to be of a different nature than those from the other samples.
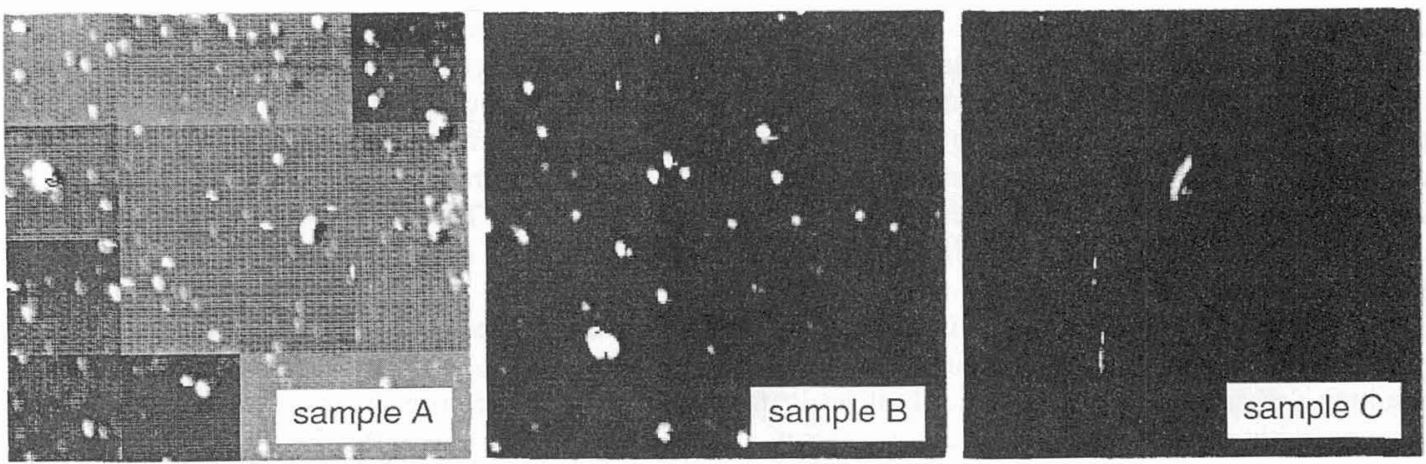

Fig. 1: Photothermal amplitude images of $800 \times 800 \mu \mathrm{m}^{2}$ areas on samples A, B and C. 

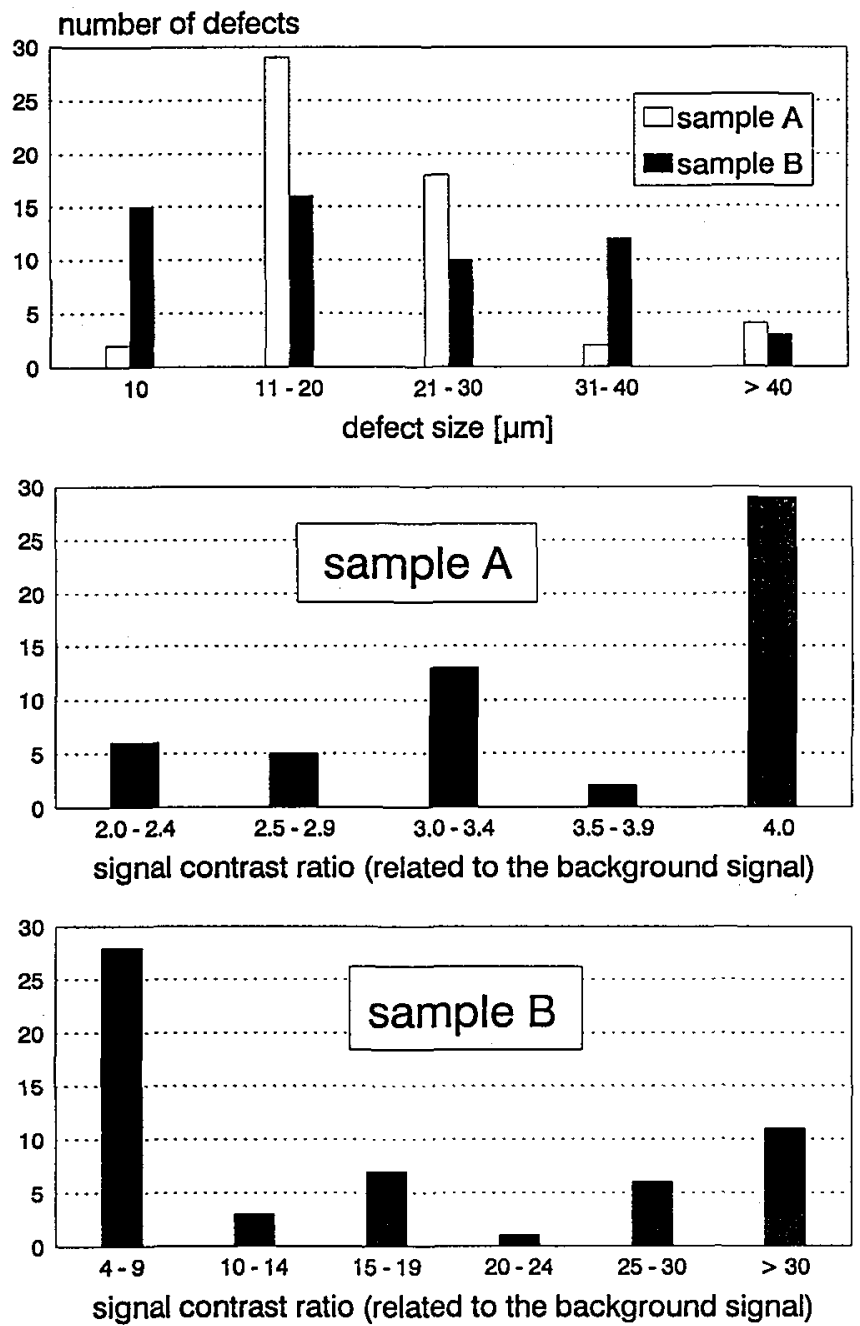

Fig. 2: Distributions for defect size and absorption contrast in photothermal amplitude images of samples A and B.
To investigate defect properties quantitatively a simple statistical analysis was applied to the absorption images of sample $A$ and $B$.

A compilation of the main results is displayed in Fig. 2. The upper graph shows the distribution of defect size for both samples in comparison. It is found that the total number of defects is about equal for both samples, however, the size distributions differ considerably. While defects are about equally distributed over the size classes for sample $B$, a distinct peak of defects between 10 and $30 \mu$ $\mathrm{m}$ is found for the lowest quality sample A.

Similar differences are found when comparing the apparent absorption contrast ratios of the two samples as displayed in the two lower charts of Fig. 2. Due to the smaller background signal for sample B a large range of absorption contrast ratios (i.e. signal at the absorption peak compared to background signal in the surroundings) is found. The statistics reveals a clear preference for small contrast ratios. For sample A, however, the distribution is peaked at the higher values.

For a correct interpretation of these results it should be kept in mind that the amplitude images in Fig. 1 have been normalized differently for better clarity and absorption levels are higher by a factor of 30 for sample A than for sample B. Consequently, even those defects in sample A with a very small absorption contrast have higher absolute absorption values than the high contrast defects in sample B. From the statistical analysis it can be concluded that the degradation of sample A is a result from both a strong homogeneously distributed background absorption as well as a certain class of strongly absorbing defects with a typical size of $20 \mu \mathrm{m}$.

\section{THERMAL EFFECTS}

In a second set of experiments photothermal microscopy was used to detect interface phenomena resulting from high fluence excimer laser irradiation. To perform measurements independent of the optical properties of the films and to yield a high photothermal signal amplitude, samples were sputtered with a $50 \mathrm{~nm} P t$ overlayer after the damaging excimer laser irradiation. It was checked by reflectivity scans that the optical response of the sputtered samples was perfectly homogeneous except at spots of laser damage where scattering caused optical losses. A typical example for a photothermal image of a coating irradiated with 


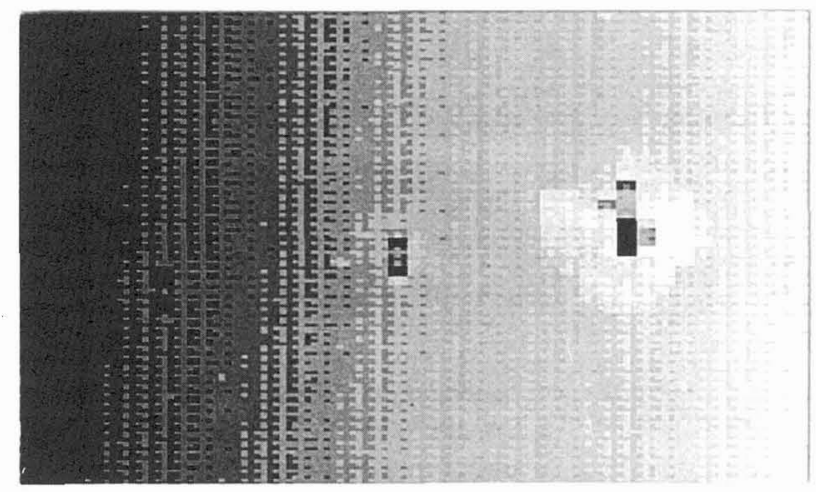

Fig. 3: Photothermal amplitude image of a Pt overcoated $\mathrm{Al}_{2} \mathrm{O}_{3} / \mathrm{SiO}_{2} / \mathrm{SQ} 1$ high reflectivity multilayer system irradiated with $248 \mathrm{~nm}$ excimer laser light.

The smooth variation of signal amplitude over the sample is an experimental artefact resulting from a small missalignment of the sample.

three different fluences is shown in Fig. 3. In this image laser damage by the rectangular excimer laser beam profile can clearly be identified in areas of reduced signal amplitude. However, each damage spot is surrounded by a halo of enhanced signal amplitude. The signal increase in these regions that have not been irradiated by the excimer laser as well as the diameter of the halo obviously depends on the fluence of the damaging radiation.

Keeping in mind that optical influences can be excluded for the interpretation of the effect, the halo clearly indicates a change of thermoelastic properties in the surroundings of damaged areas. We believe that the signal enhancement is caused by a delamination of the thin film resulting from a thermoelastic shock wave launched by the damage process. This interpretation is supported by the fact that the halo area increases with laser fluence. It is not yet completely clear, however, whether the enhanced thermal interface resistance in the delaminated area is solely responsible for the increased photothermal signal or also the changed elastic properties of the delaminated film. The latter interpretation is supported, however, by the observation that there is only a negligibly small contrast in the phase of the photothermal signal indicating that thermal phenomena do not play a major role. More detailed investigations on that point including a comparison of displacement images with photothermal reflectance scans are presently in progress.

\section{ACKNOWLEDGEMENTS}

The authors would like to express their sincere appreciation for stimulating discussions and continued support for this project by E. Matthias. This work was supported by the Sonderforschungsbereich 337 of the Deutsche Forschungsgemeinschaft.

\section{REFERENCES}

[1] Becker J. and Bernhardt A., "ISO 11254, an International Standard for the Determination of the Laser Induced Damage Threshold", Laser Induced Damage in Optical Materials SPIE 2114 (1994), in print

[2] Kozlowski M.R., Thomas I.M., Campbell J.H., Rainer F., "High-Power Optical Coatings for a Mega-Joule Class ICF Laser", Thin Films for Optical Systems SPIE 1782 (1993) pp. 105-119

[3] Itoh M., Endo A., Kuroda K., Watanabe S., Ogura I., "Laser-induced damage thresholds and absorption measurements in rare-gas-halide excimer laser components"

Opt. Comm. 74 (1989) p. 253-260

[4] Mann K. and Gerhardt H., "Setup of a damage testing facility for excimer laser radiation", Proceedings SPIE 1023 (1988) pp. 136-140

[5] Welsch E., Reichling M., "Micrometer resolved photothermal displacement inspection of optical coatings", J. Mod. Opt. 40(8) (1993) 1455-1475

[6] Reichling M., Welsch E., Duparré A., Matthias E., "Photothermal absorption microscopy of defects in $\mathrm{ZrO}_{2}$ and $\mathrm{MgF}_{2}$ single-layer films", Opt. Eng. (1994), in print 